\title{
AIN/CrN multilayer structures with increased thermal stability
}

\author{
Shiyu Liu ${ }^{1 *}$, Yi Yang ${ }^{2}$, Rong Ji², X. T. Zeng ${ }^{1}$, W.J. Clegg ${ }^{3}$ \\ ${ }^{1}$ Singapore Institute of Manufacturing Technology, 2 Fusionopolis Way, Singapore 138634. \\ ${ }^{2}$ Data Storage Institute, 2 Fusionopolis Way, Singapore 138634. \\ ${ }^{3}$ Gordon Laboratory, Department of Materials Science and Metallurgy, 27, Charles Babbage \\ $R d$, Cambridge CB3 OFS, U.K.
}

\begin{abstract}
CrAlYN nanolayered coatings of greatly enhanced thermal stability have been developed by doping with levels of Y up to 9 at\%. This prevented the complete dissolution of the layered structure after annealing at $1,100{ }^{\circ} \mathrm{C}$ in Ar for 1 hour, commonly observed in coatings with little or no $\mathrm{Y}$ content, although the bilayer period increased from $\sim 5 \mathrm{~nm}$ to $\sim 10 \mathrm{~nm}$. The improved thermal stability is attributed to the formation of a continuous YN layer between the $\mathrm{CrN}$ and $\mathrm{AlN}$ layers, reducing the rate of interdiffusion.
\end{abstract}

\section{Keywords}

Thermal stability; diffusion; nanolayered coating; AlN/CrN; 
Increasing the rate at which metal is machined offers a way of significantly reducing manufacturing costs. However, in high-speed, dry machining the temperature at the tool tip can rise to temperatures as high as $1,100{ }^{\circ} \mathrm{C}$. Any hard coating must therefore be able to withstand temperatures of this magnitude. It is known that multi-layered coatings can provide significant advantages in particular in terms of wear resistance[1]. However, work elsewhere has shown that such multilayer structures will pinch off, at temperatures as low as $900{ }^{\circ} \mathrm{C}$, leading to complete disintegration of the multilayer structure within only 15 minutes[2]: an example of a Rayleigh instability driven by capillary forces[3]. Although this was originally described for liquids, related processes occur in the solid state[4]. If such structures are to be useful, dramatic improvements in the thermal stability are required.

It has been shown that improvements can be obtained by adding $\mathrm{Y}$, provided the $\mathrm{Y}$ content does not exceed $\sim 1$ at $\%$ [5]. This limit has been associated with a reduced oxidation resistance as non-protective forms of alumina are formed and an increased tendency for the c-AlN layers to transform to h-AlN, causing a decrease in hardness[6]. In this paper, it is shown that hard multilayer coatings can be made with $\mathrm{Y}$ concentrations as high as 9 at $\%$, enabling the multilayer structure to be preserved even after heating at temperatures as high as $1,100^{\circ} \mathrm{C}$, for times as long as 1 hour.

CrN/AlN nanolayered coatings with different Y doping levels were deposited on high speed steel (HSS) by a hybrid HIPIMS - magnetron sputtering disposition system (CemeCon 800/9, CemeCon AG) at bias voltage of $-10 \mathrm{~V}$ and substrate temperature of $600{ }^{\circ} \mathrm{C}$. A total of six targets were used during the deposition, where the $\mathrm{Cr}$ and $\mathrm{Al}$ targets were connected to conventional DC power sources while the Y targets were connected to HIPIMS power source to intensify the Y bombardment (see Fig. S1 in Supplementary Materials). During deposition, the power supplied to the $\mathrm{Cr}$ and $\mathrm{Al}$ targets was constant, while that for the $\mathrm{Y}$ target increased 
in each batch, giving coatings with a similar $\mathrm{Cr} / \mathrm{Al}$ ratio, but an increasing $\mathrm{Y}$ content. The coatings were approximately 4-5 $\mu \mathrm{m}$ thick and with surface roughness, $\mathrm{Ra}$, of $\sim 10 \mathrm{~nm}$.

The coating composition was determined by energy dispersive spectroscopy (Oxford Instrument, UK) on a field emission scanning electron microscope (FESEM) (GeminiSEM, Zeiss) at an accelerating voltage of $20 \mathrm{kV}$. The thermal stability of the coatings was investigated by heating the coatings to $1,100{ }^{\circ} \mathrm{C}$ in a tube furnace at a heating rate of $5{ }^{\circ} \mathrm{C} \mathrm{min}{ }^{-1}$ under flowing Ar. The samples were held at $1,100{ }^{\circ} \mathrm{C}$ for 1 hour, before cooling to room temperature at $5{ }^{\circ} \mathrm{C} \mathrm{min}{ }^{-1}$. The coating microstructure and elemental distribution both before and after the heat treatment were characterized by FESEM (GeminiSEM, Zeiss), high resolution transmission electron microscopy (HRTEM) and electron energy loss spectroscopy (EELS) mapping (Tecnai G2 F20, FEI).

The as-deposited coatings had a columnar nature with an average column width of 200$400 \mathrm{~nm}$, Fig. 1. The multi-layered coatings had a thickness before heat treatment of $\sim 2 \mathrm{~nm}$ ( 8-10 monolayers) and $\sim 3 \mathrm{~nm}(\sim 11-15$ monolayers) for the $\mathrm{AlN}$ and $\mathrm{CrN}$ layers, respectively. This is consistent with chemical composition of the coatings, in which the atomic ratio of $\mathrm{Cr} / \mathrm{Al}$ is approximately 1.5 , Table 1 . The $\mathrm{Cr} / \mathrm{Al}$ ratio increased slightly with $\mathrm{Y}$ content. This is possibly caused by the bombardment of the AlN layer by Y, causing resputtering of Al. For the coating with Y content of $\sim 4$ at $\%$, EELS mapping showed the $\mathrm{Y}$ was preferentially absorbed in to the AlN layer, Fig. 1(c), consistent with the observation of greater lattice distortion in the AlN layer, Fig. 1(e), although some Y was also seen in the $\mathrm{CrN}$ layers. The coating appeared crystalline and epitaxial growth of the f.c.c. CrN structure across the CrN/AIN interface could be observed. When the $\mathrm{Y}$ content was increased to $\sim 9$ at\%, continuous Y-rich layers were formed on top of the AlN layers, Fig. 1(d). It is noted that the distribution of $\mathrm{N}$ content is uniform across the $\mathrm{Al}, \mathrm{Cr}$, and $\mathrm{Y}$ layers, (see Fig. S2 in 
Supplementary Materials), and since YN has an enthalpy of formation even lower than that of CrN [7], it seems most likely that the Y rich layer exists as YN. The interface between the YN and AlN layers was less well-defined, suggesting some intermixing of the two. This is presumably due to the high energy bombardment of the heavy Y ions, and is associated with a partial amorphisation of the AIN layers, Fig. 1(f).

The coating microstructures after annealing in Ar at $1,100{ }^{\circ} \mathrm{C}$ are presented in Fig. 2. In the Y-free coating it can be seen that the layered structure has completely disappeared. A dense layer rich in $\mathrm{Cr}$ and $\mathrm{Fe}$, from both the coating and the substrate, was also observed on the coating surface.

Similar observations were made in the CrAlYN coating with 0.5 at $\%$ Y, except that the $\mathrm{Cr} / \mathrm{Fe}$ layer only half as thick. However, for coatings containing $\sim 4$ at $\% \mathrm{Y}$, the layer of $\mathrm{Cr}$ and $\mathrm{Fe}$ did not form. Instead, vertical features that appeared to be associated with the column boundaries were observed.

Further increasing the $\mathrm{Y}$ content to 6 at $\%$ eliminated the formation of vertical bands, and some layered structures with round shaped features distributed along them could be seen. For Y contents of $\sim 9$ at $\%$, the annealed coating appeared featureless in the SEM image after heating at $1,100{ }^{\circ} \mathrm{C}$.

To study the effect of $\mathrm{Y}$ on the thermal stability of the coatings in more detail, the microstructure of the annealed CrAlYN coatings were examined using HRTEM and EELS mapping, Fig. 3.

This showed that in the coating containing $\sim 4$ at $\%$ Y, the multilayer structure dissolved with Cr-rich phases, 20-30 $\mathrm{nm}$ in diameter, being deposited on the column boundaries, giving rise to the vertical features described above. As the thermal expansivity of the HSS steel[8] 
$\left(\sim 12 \times 10^{-6} \mathrm{~K}^{-1}\right)$ is much greater than that of both the $\mathrm{CrN}[9]\left(\sim 2.3 \times 10^{-6} \mathrm{~K}^{-1}\right)$ and the AlN[9] $\left(\sim 5.7 \times 10^{-6} \mathrm{~K}^{-1}\right)$. Assuming that the coating is essentially stress-free at the deposition temperature of $600{ }^{\circ} \mathrm{C}$, not unreasonable as the substrate bias is only $-10 \mathrm{~V}$, increasing the temperature to $1,100{ }^{\circ} \mathrm{C}$ will place both layers in the coating in tension. Using the Young modulus and Poisson ratios for $\mathrm{CrN}$ and $\mathrm{AlN}$ from the literature [10-12], it is estimated in that the thermal stresses in the coatings are approximately $1.8 \mathrm{GPa}$ (See Appendix $\mathrm{A}$ in Supplementary Material). As the stresses on the horizontal interfaces are $\sim 0$, there is a driving force for a flux of $\mathrm{Cr}$ atoms from the horizontal interfaces to the vertical column boundaries [13], causing the Cr-rich phases to form.

Diffusional flow may not be the only way in which matter is transported. Extrapolating the decrease in the compressive yield stress with temperature [14], the yield stress at $1,100{ }^{\circ} \mathrm{C}$ is estimated to be $\sim 1.5 \mathrm{GPa}$, suggesting that thermal mismatch may also drive plastic flow. It is also estimated that the elastic strains are approximately $4 \times 10^{-3}$ (See Appendix $\mathrm{A}$ in Supplementary Material). This is within what might be reasonably considered an elastic strain, suggesting that further boundaries are not developed by cracking of the layers during heating to $1,100{ }^{\circ} \mathrm{C}$.

Although the CrAlYN coating with 9 at\% Y appeared featureless in the SEM, HRTEM showed that the layered structure was retained after the heat treatment, although the thickness of the bilayers had doubled from $\sim 5 \mathrm{~nm}$ to $\sim 10 \mathrm{~nm}$. In the CrN layers, the intensity of the signal from the $\mathrm{N}$ atoms appeared lower than that in the Al-rich layers, Fig. 3(f), consistent with the loss of $\mathrm{N}$ observed in $\mathrm{CrN}$ and the good thermal stability of AlN at these temperatures [15]. Atoms in the Cr-rich layer appeared to be diffusing towards the columnar boundaries, joining those from adjacent columns and closing any gap across the columnar boundary, Fig. 4. 
HRTEM images suggest the coating to be multilayered and highly crystalline with sharp interfaces between the Cr-rich and Al-rich phases, Fig. 4. The electron diffraction patterns show that the Cr-rich layers have a cubic crystal structure. However the Al-rich layers have a hexagonal crystal structure, Fig. 4, consistent with the phase transformation reported in the literature[6]. It was also noted that most Cr-rich layers have dark outlines 3-4 monolayers in thickness on both sides, which appear to contain Y, presumably as YN. Calculations $[6,16]$ have shown that the enthalpy of mixing of $\mathrm{YN}$ is more positive, i.e. less favorable, than any other metal nitride in $\mathrm{CrN}$ and $\mathrm{AlN}$. This suggests that $\mathrm{YN}$ will not easily dissolve in c-AlN or c-CrN. Furthermore, work elsewhere, using the AlN-YN system to make semiconductor single crystals, has confirmed the existence of a deep eutectic in this system at $2,055^{\circ} \mathrm{C}$ [17]. Below this temperature $\mathrm{AlN}$ and $\mathrm{YN}$ will exist as separate phases in thermodynamic equilibrium with one another. That the two phases do not readily mix and hence are not soluble in one another, even at elevated temperatures, is consistent with the observations by HRTEM, suggesting that the YN layer would act as a diffusion barrier.

The formation of the Cr-rich phases on the columnar boundaries at low Y concentrations, where an amorphous layer is formed, e.g. 4 at $\%$, suggest that diffusion within a layer can occur readily. However, at higher Y concentrations, e.g. 9 at\%, which has most likely given rise to $\mathrm{YN}$ after heat treatment, these Cr-rich phases do not form, indicating that any lateral diffusion was suppressed. It is known that refractory second phases at grain boundaries will inhibit diffusional processes, as refractory particles find it difficult to move through a matrix[18-20]. Similar effects have also been observed in ceramics containing fine particles[21], and one might expect that the formation of a continuous layer of $\mathrm{YN}$ was even more effective at reducing the rate of diffusional creep. 
As the thickening of layers is a result of the interdiffusion of $\mathrm{AlN}$ and $\mathrm{CrN}$ layers, a rough estimate of diffusivity of the process at $1,100{ }^{\circ} \mathrm{C}$ could be made. Assume the layers doubled their thickness by moving one AlN layer across the neighboring $\mathrm{CrN}$ layer, the distance travelled by $\mathrm{Al}$ atoms will be the thickness of the $\mathrm{CrN}$ layer, i.e. $3 \mathrm{~nm}$. If we further assume the diffusion process only take place during the one hour annealing at $1,100{ }^{\circ} \mathrm{C}$, the diffusion coefficient, $D$, could be estimated by

$$
D=\frac{x^{2}}{2 t}
$$

where $x$ and $t$ are the distance and time of the diffusion process, respectively, giving a value for $D$ of $1.25 \times 10^{-21} \mathrm{~m}^{2} \mathrm{~s}^{-1}$. This value is about two orders lower than the diffusivity of $\mathrm{Al}$ in c-TiN[22], which has the same $f c c$ structure as $\mathrm{c}-\mathrm{CrN}$, though it is unfortunate that no diffusivity data on $\mathrm{Al}$ diffusing in $\mathrm{c}-\mathrm{CrN}$ lattice is available. This is again consistent with the idea that the rate of diffusion across the YN layers is suppressed.

Films containing $\mathrm{Y}$ levels as high as 9 at $\%$ have been made and their thermal stability characterised. After heating at $1,100{ }^{\circ} \mathrm{C}$, the bilayer period increases by a factor of two. However, the multilayer structure remains otherwise intact, whereas in films with lower or no Y content, complete disintegration of the multilayer structure has been observed. The outward diffusion of $\mathrm{Cr}$ and $\mathrm{Fe}$ to the coating surface was also substantially reduced by the $\mathrm{Y}$ addition. The enhanced thermal stability is attributed to the presence of an YN layer, which acts as a diffusion barrier. As a result of the high mixing enthalpy, the YN layer exists in thermodynamic equilibrium with the $\mathrm{AlN}$ and $\mathrm{CrN}$ as separate phases, rather than dissolving in either, consistent with the observations here, calculation and crystal growth experiments. 


\section{Acknowledgements}

The authors would like to acknowledge Dr. Tao Li and Mr. Hao Li Toh for their help with the sample heat treatment.

\section{References}

[1] S. Paldey, S.C. Deevi, Mater. Sci. Eng. A 342 (2003) 58-79.

[2] D. Tytko, P.P. Choi, D. Raabe, Acta Mater. 85 (2015) 32-41.

[3] L. Rayleigh, Philos. Mag. 34 (1892) 37-41.

[4] F.A. Nichols, W.W. Mullins, J. Appl. Phys. 36 (1965) 1826-1835.

[5] F. Rovere, P.H. Mayrhofer, J. Vac. Sci. Technol. A Vacuum, Surfaces, Film. 26 (2008) 29.

[6] F. Rovere, D. Music, J.M. Schneider, P.H. Mayrhofer, Acta Mater. 58 (2010) 27082715 .

[7] A.K. Niessen, F.R. De Boer, J. Less-Common Met. 82 (1981) 75-80.

[8] F. Cverna, ASM Ready Reference: Thermal Properties of Metals, ASM International, 2002.

[9] H. Holleck, J. Vac. Sci. Technol. A Vacuum, Surfaces, Film. 4 (1986) 2661.

[10] S. Liu, R. Raghavan, X.T. Zeng, J. Michler, W.J. Clegg, Appl. Phys. Lett. 104 (2014) 081919.

[11] U. Wiklund, M. Bromark, M. Larsson, P. Hedenqvist, S. Hogmark, Surf. Coatings Technol. 91 (1997) 57-63.

[12] J.-M. Wagner, F. Bechstedt, Phys. Rev. B 66 (2002) 1-20.

[13] C. Herring, J. Appl. Phys. 21 (1950) 437-445.

[14] S. Liu, J.M. Wheeler, J. Michler, X.T. Zeng, W.J. Clegg, Scr. Mater. 117 (2016) 2427.

[15] A. Abid, R. Bensalem, B.J. Sealy, J. Mater. Sci. 21 (1986) 1301-1304.

[16] L. Zhou, D. Holec, P.H. Mayrhofer, J. Phys. D. Appl. Phys. 46 (2013) 365301.

[17] G. Slack, S. Schujman, Deep-Eutectic Melt Growth of Nitride Crystals, US008088220B2, 2012.

[18] W.J. Clegg, J.W. Martin, Met. Sci. 16 (1982) 65-72.

[19] M.F. Ashby, R.M. Gentamore, Acta Metall. 16 (1968) 1081-1092.

[20] M.F. Ashby, Scr. Metall. 3 (1969) 837-842. 
[21] J.E. Pitchford, E. Lidén, S. Gustafsson, L.K.L. Falk, E. Carlström, W.J. Clegg, Key Eng. Mater. 317-318 (2006) 445-448.

[22] G.I. Grigorov, K.G. Grigorov, M. Stoyanova, J.L. Vignes, J.P. Langeron, P. Denjean, Appl. Phys. A Solids Surfaces 57 (1993) 195-197. 
Tables

TABLE 1: Composition of the as-deposited CrAIN and CrAIYN coatings.

\begin{tabular}{lccccc}
\hline \hline & \multicolumn{4}{c}{ Composition (at\%) } & \multirow{2}{*}{$\begin{array}{c}\text { Cr/Al } \\
\text { ratio }\end{array}$} \\
\cline { 2 - 5 } \multicolumn{1}{c}{ Sample } & $\mathrm{N}$ & $\mathrm{Al}$ & $\mathrm{Cr}$ & $\mathrm{Y}$ & 1.47 \\
\hline CrAlN & 50.1 & 20.2 & 29.7 & & 1.47 \\
CrAlYN-1 & 50.5 & 19.8 & 29.2 & 0.5 & 1.47 \\
CrAlYN-2 & 49.9 & 19.6 & 28.5 & 2.0 & 1.45 \\
CrAlYN-3 & 49.4 & 18.4 & 28.3 & 3.9 & 1.54 \\
CrAlYN-4 & 49.9 & 17.5 & 26.4 & 6.2 & 1.51 \\
CrAlYN-5 & 49.9 & 15.7 & 25.3 & 9.1 & 1.61 \\
\hline \hline
\end{tabular}




\section{Figures}

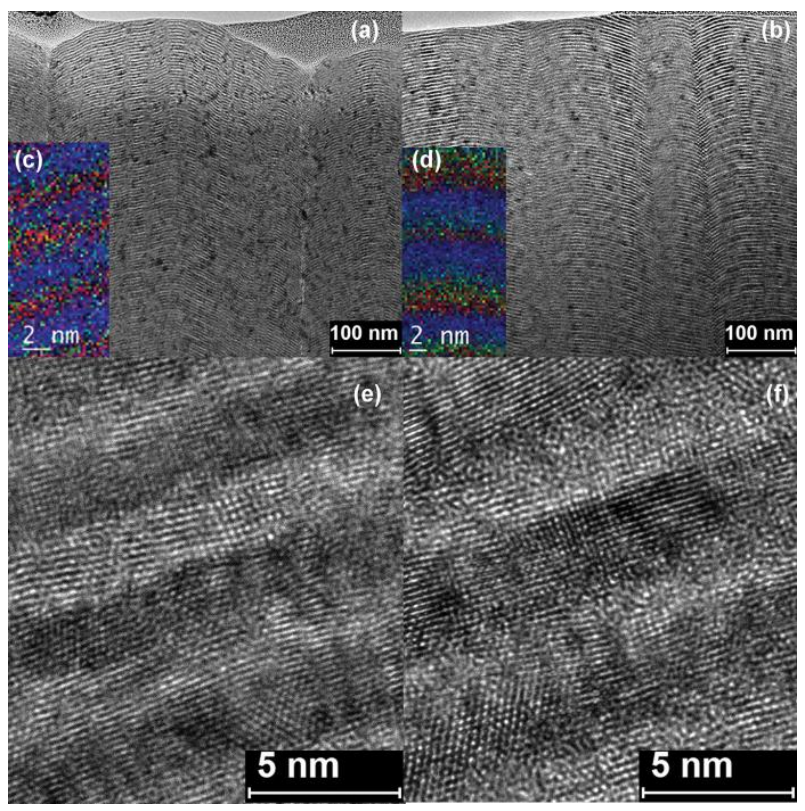

FIG. 1 TEM, EELS mapping and HRTEM of CrAIYN coatings with 4 at\% Y content (a), (c) and (c) and 9 at\% Y content (b), (d) and (f). Note that in (c) and (d), blue, red and green colours indicate the presence of $\mathrm{Cr}, \mathrm{Al}$ and $\mathrm{Y}$ elements.

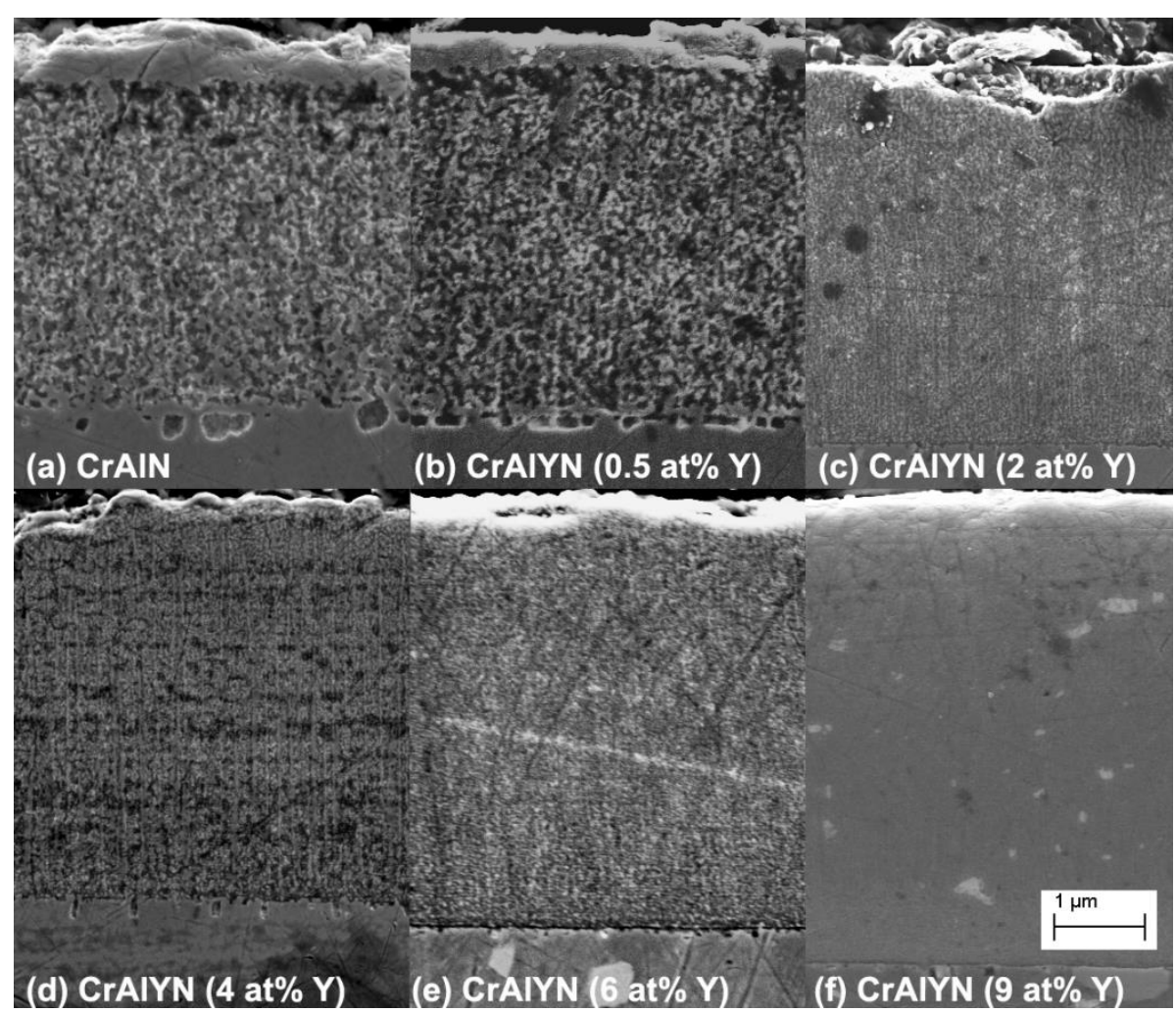

FIG. 2 Cross sectional SEM images of heat treated CrAlN and CrAlYN coatings with different $\mathrm{Y}$ content. 


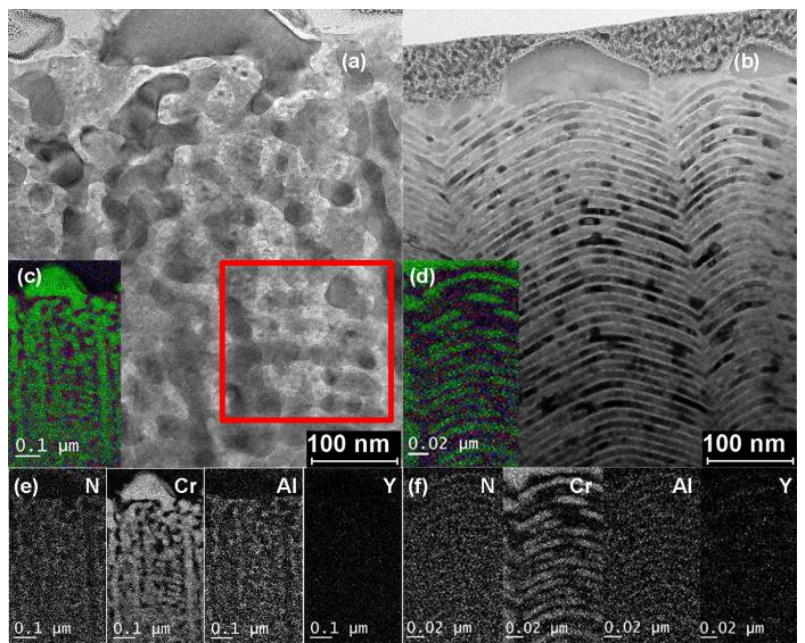

FIG. 3 TEM images and EELS mapping of CrAlYN coatings with 4 at\% Y content (a), (c) \& (e) and 9 at\% Y content (b), (d) \& (f) respectively. In (c) and (d) green, red and blue colour represent the presence of $\mathrm{Cr}, \mathrm{Al}$ and $\mathrm{N}$ elements. The red square contains what could be the coarsened and spheroidised layers.

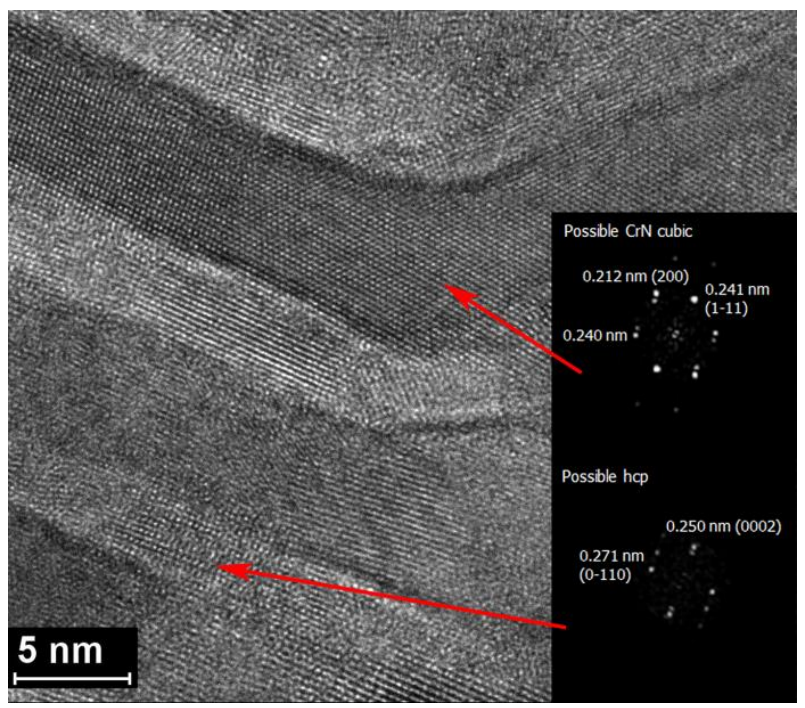

FIG. 4 High resolution TEM image of annealed CrAlYN coating with 9 at $\%$ Y content at where used to be a columnar boundary prior to the heat treatment. The electron diffraction patterns of the dark and bright layers suggest they are likely to be cubic $\mathrm{CrN}$ and hexagonal $\mathrm{AlN}$ related phases, respectively. The dark outlines, 3-4 monolayers in thickness along both sides of the Cr-rich layer, are likely consist of heavier Y atoms, which appear darkest in HRTEM. 